OPEN ACCESS

Edited by:

Holly J. Niner,

University of Plymouth,

United Kingdom

Reviewed by:

Ranjan Datta,

Mount Royal University, Canada

William Atlas,

Wild Salmon Center, United States

*Correspondence:

Julia A. Bingham

julia.bingham@duke.edu

Specialty section:

This article was submitted to

Marine Conservation

and Sustainability,

a section of the journal

Frontiers in Marine Science

Received: 23 February 2021

Accepted: 26 March 2021

Published: 04 May 2021

Citation:

Bingham JA, Milne S, Murray G and Dorward T (2021) Knowledge Pluralism in First Nations' Salmon

Management.

Front. Mar. Sci. 8:671112. doi: 10.3389/fmars.2021.671112

\section{Knowledge Pluralism in First Nations' Salmon Management}

\author{
Julia A. Bingham ${ }^{1 *}$, Saul Milne², Grant Murray ${ }^{1}$ and Terry Dorward ${ }^{3}$ \\ ${ }^{1}$ Duke University Marine Laboratory, Nicholas School of the Environment, Duke University, Beaufort, NC, United States, \\ ${ }^{2}$ Department of Geography, University of Victoria, Victoria, BC, Canada, ${ }^{3}$ Tribal Parks Department, Tla-o-qui-aht First \\ Nation, Tofino, BC, Canada
}

There is growing interest in the "integration" of knowledge and values held by Indigenous peoples with Western science into natural resource governance and management. However, poorly conducted integration efforts can risk harming Indigenous communities and reifying colonial legacies. In this regard, dichotomous conceptualizations of Indigenous and scientific knowledges are problematic. In this research, we focus on the role of indigenous and scientific knowledges in the management of coho salmon (Oncorhyncus kisutch) on the west coast of Vancouver Island, British Columbia (BC) in a governance context featuring contested authority among First Nations (Indigenous peoples) and the government of Canada. We discuss an example from a particular Indigenous community, Tla-o-qui-aht First Nations (TFN), that has worked with other management bodies to establish practices for the restoration, enhancement and harvest of cuwíit (coho). After outlining relevant Tla-o-qui-aht values, knowledges and decision-making processes, we consider the pluralistic approach to Indigenous and scientific knowledges in Tla-o-qui-aht management of cuwit and show that pluralistic, co-constitutive, and multiplicative understandings of Indigenous and scientific ways of knowing may provide better grounding for addressing challenges in integration efforts. We also emphasize the importance of engagement with FN community liaisons and deferral to FN leadership to align management efforts with FN structures of knowledge production and governance, maintain ethical engagement, recognize Indigenous agency, and support effective conservation, and management efforts.

Keywords: knowledge pluralism, Indigenous knowledge, fisheries management, fisheries governance, knowledge integration, western science, salmon, pacific northwest

\section{INTRODUCTION}

There is growing interest in the "integration" of Western science with the knowledge and values held by Indigenous peoples into natural resource governance and management. The stated intents of these efforts to "bridge" or "integrate" IK with western science include enriched ecological knowledge, improved decision-making processes and outcomes in conservation and management, and empowerment of Indigenous peoples (Berkes, 2009; Weiss et al., 2013; Mistry and Berardi, 2016; Ban et al., 2018; Whyte, 2018; Thompson et al., 2019, 2020; Wheeler and Root-Bernstein, 2020; Reid et al., 2020). Some of this work has cautioned against "integration" efforts that feature an artificial dichotomization of these knowledge systems, appropriation of one knowledge into another based on perceived utility to western scientific management objectives, 
or conditional validation where non-scientific knowledges are only accepted as legitimate if they match assumptions in western science (Weiss et al., 2013; Mistry and Berardi, 2016; Reid et al., 2020). Such integration efforts serve to echo harmful colonial histories, displace Indigenous values and worldviews, limit the agency of Indigenous peoples and marginalize their own decision-making processes, precipitate negative ecological and socio-cultural outcomes, and contribute to Indigenous peoples' distrust of Federal governments (Whyte, 2013; Coombes et al., 2014; Muller et al., 2019). In this article, we build on work that challenges this legacy and pushes toward equitable, just, and decolonized practices in resource management.

In the academic literature, Indigenous knowledge (IK), often termed traditional ecological knowledge (TEK), broadly refers to environmentally oriented ways of knowing which are placebased, adaptive, acquired experientially and intergenerationally, and held by Indigenous peoples (Berkes, 2012; Ban et al., 2018; Wheeler and Root-Bernstein, 2020). IK is contextualized by specific worldviews and cultural practices and formed through close relationships with the local environment and with community (Berkes, 2012; Thompson et al., 2020). There is no single IK system, and IK cannot be selectively described through discrete pieces of information; knowledge is embedded within the worldview and traditional practices of an Indigenous community (Wheeler and Root-Bernstein, 2020). English language and academic articulation of IK/TEK originated in international development and adaptive governance literature (Agrawal, 1995; Whyte, 2013). These definitions are sometimes embedded in controversy and tend to privilege non-Indigenous and scientific agendas or frame IK/TEK as a way to fill gaps in scientific knowledge through assimilation (Whyte, 2013; Reid et al., 2020).

In seeking a clear definition of IK/TEK and an articulation of the differences and relationships between science and IK/TEK, Indigenous and scientific ways of knowing are often treated dichotomously. Mistry and Berardi (2016) among others (Whyte, 2013; Weiss et al., 2013; Reid et al., 2020) note that science has been framed as superior in accuracy, rigor, objectivity, modernity and reliability. Some academic literature has specified science as different from IK/TEK through its systematic processes and positivist or reductionist perspectives and in noting that science is perceived, if erroneously, to be more objective and less culturally embedded than Indigenous ways of knowing (Weiss et al., 2013; Muller et al., 2019). Hypothesis and experiment-driven science and (especially quantitative) data is often contrasted with place-based, relationally-driven, experiential knowledge shared through storytelling, ceremony, and other oral traditions (Ban et al., 2018; Wheeler and Root-Bernstein, 2020). However, these differentiations are not absolute, nor do they inherently make science more accurate or relevant. There are also clear epistemic similarities in these knowledge systems. Both scientific and Indigenous ways of knowing rely on observation, occur through culturally embedded processes, develop through integration of new technologies, and can seek to understand ecological systems and the impacts of human behavior (Kimmerer, 2013a; Weiss et al., 2013; Ban et al., 2018). Differences between Indigenous and scientific ways of knowing are more ontologically grounded; for example Indigenous ways of knowing center relational worldviews (Datta, 2015) and a focus on connection, compared to practices of categorization or separation in western knowledge traditions (Muller, 2012).

Indigenous scholars Marshall (Bartlett et al., 2012), Kimmerer (2013a,b), and Whyte (2013, 2018), among others, reject ideas of a hierarchical division between science and IK, the supposed objectivity of western science, and the categorization of IK as antiquated, lacking rigor, or dependent on myth. They argue that dichotomous views of Indigenous and scientific ways of knowing preclude collaborative relationships and shared understanding between Indigenous peoples and environmental scientists and conservation practitioners. Further, recognition of IK as valid alongside rather than mediated or subjugated by science is important for disrupting colonial legacies in resource governance and for more effectively integrating knowledges into management efforts (Whyte, 2013; Muller, 2014; Reid et al., 2020).

The challenges of knowledge integration efforts are exemplified in salmon fisheries of the west coast of Vancouver Island, BC, Canada (WCVI) where governance features contested sovereignty between Canada and First Nations (Indigenous peoples). In this paper, we discuss an example from Tla-o-qui-aht First Nations (TFN) and the management of coho salmon (Oncorhynchus kisutch) on WCVI. We describe TFN's management priorities for coho, contextualized through Tla-o-qui-aht worldview, and consider the roles of western science and IK in TFN's salmon governance and management. We demonstrate a practice of integration that enacts knowledge pluralism embedded in the salmon governance and management of TFN. In this case, knowledge pluralism refers to the idea that Indigenous and scientific knowledges are fluid, evolving ways of knowing that are mutually informative and may be concurrently mobilized. We conceptualize knowledge plurality by drawing on epistemic pluralism (Carter, 2017) and on Indigenous frameworks for knowledge coexistence which reflect a philosophy and practice of embracing collaborative knowledge generation, recognizing strengths in Indigenous and scientific knowledges, and rejecting dichotomous definitions between knowledge systems (Whyte, 2013; Reid et al., 2020). Our use of the term "pluralism" is reflective of ontological multiplicities discussed by Mol (1999) and Howitt and Suchet-Pearson $(2003,2006)$ and requires attention to Indigenous diversity and particularities (Howitt et al., 2009).

The specific details in this article directly stem from a 6 year research project entitled EPIC4 ${ }^{1}$ that utilizes western science and is intended to support application of conservation tools and technology to coho salmon management. EPIC4 itself grew out of a long-term engagement between authors on this project through multiple research-oriented projects spanning close to 15 years that have built considerable trust, identified shared areas of interest and that have collectively sought to maintain

${ }^{1}$ EPIC4 (Enhanced Production in Coho: Culture, Community, Catch) is an ongoing research project, funded from outside of the Tla-o-qui-aht community, seeking to address challenges in coho salmon conservation and management through genomics. This paper does not explicitly consider genomics. It is part of one section of EPIC4 focused on First Nations' knowledge mobilization and project impacts to community well-being. 
ethical engagement with First Nations' governance structures and uphold First Nations' agency. The specific goals of this article are to illuminate Tla-o-qui-aht values, worldviews and knowledge development and decision-making processes relevant to the management of coho and to demonstrate the strengths of a practice of knowledge pluralism that differs from most western scientific management or academic approaches of knowledge integration.

\section{METHODS}

\section{Case Study: Tla-o-qui-aht First Nations}

The traditional territory (hahouthli) of the Tla-o-qui-aht First Nations (TFN) is on the west coast of Vancouver Island and encompasses Clayoquot Sound, three Tla-o-qui-aht communities, and the Canadian town of Tofino. TFN is one of fourteen language-sharing Nuu-chah-nulth First Nations who have lived along the west coast of Vancouver Island for thousands of years. The history between Nuu-chah-nulth people and Canada following white settlement includes violent displacement, forced assimilation, resource disputes, and contested sovereignty. First Nations have well-established structures of resource governance but have historically been subjugated by de jure and de facto practices of Canadian governance systems (Truth and Reconciliation Commission, 2015; Ban et al., 2019). The history of conflict over territory and resource use rights between Canada and First Nations complicates tense and often antagonistic negotiations over fishery management decisions.

Canada attempts to accommodate asserted food, social, and ceremonial (FSC) fishing rights of each Nuu-chah-nulth First Nation and, after lengthy and ongoing struggles in the courts, recently recognized the commercial fishing rights of five Nations, including Tla-o-qui-aht (CanLII, 2018). T'aaq-wiihak (fishing with the permission of the chiefs) and Ha'oom Fisheries Society were developed to coordinate negotiating and implementing these rights. T'aaq-wiihak negotiates with Fisheries and Oceans Canada (DFO) to determine catch allocations, season openings and lengths, and other restrictions. Ha'oom works collaboratively with each of the five Nations to implement the results of negotiations through managing demonstration commercial fisheries and establishing local practices for the catch monitoring, restoration, enhancement, and harvest of salmon populations. Recent modification of the Fisheries Act (Bill C-68, 2019) includes a directive for DFO to incorporate Indigenous rights and knowledge into fishery management practices and to strengthen obligations to build partnerships with First Nations. While Federal strategies toward meeting this legislative mandate are evolving, Tla-o-qui-aht and other FNs have developed their own strategies of applying traditional and scientific knowledges in territorial resource governance and management. TFN hopes to eventually hold full agency over the management of fish stocks within their traditional territories.

The five species of Salmon (Oncorhynchus spp.) native to $\mathrm{BC}$ waters hold high economic value to many coastal BC communities and are integral to the well-being of Nuu-chahnulth First Nations on Vancouver Island (George, 2003; Atleo,
2011; Price et al., 2017). Wild salmon populations across British Columbia (BC) have not recovered from drastic declines despite fishery closures and population supplementation through hatchery propagation (Price et al., 2017). Recent escapement surveys estimate coho numbers in the Tla-o-qui-aht watersheds to be at a fraction of the 12 year average, and some river surveys report returning coho numbers in the single digits (DFO, 2019a,b, 2020). Management is complicated by a limited ability to differentiate wild from hatchery fish, identify spawning origins of wild fish, prevent genetic introgression, and to easily identify wild fish as part of specific Conservation Units (Price et al., 2017). With these challenges in mind, First Nations and DFO are highly invested in salmon conservation and management using both Indigenous knowledges (IKs) and scientific tools.

\section{Information and Analysis}

Our approach used ethnographic traditions grounded in critical theory within a western research paradigm that was also informed by the growing literature on indigenous methodologies. A western research paradigm is limited in its ability to account for and incorporate Indigenous worldviews, so we referred to Smith (2012) and the reflections of Coombes et al. (2014), and Reid (2020) on the praxis of appropriately engaging in critical research with an Indigenous community, especially regarding the importance of Indigenous leadership. Further, we centered relational ontologies in our conceptual framework (Datta, 2015) and placed ethics and reciprocity as central to the methodology (Kovach, 2010).

We prioritized direction by and meaningful engagement with TFN, building on a 15 year history of work together. TFN representatives led our conversations toward developing research objectives and we followed TFN's formal permission guidelines to conduct the research and write about Tla-o-qui-aht knowledge, governance, and management practices. All research objectives, methods of data collection, and agreements on data and research ownership were first reviewed and approved by TFN through the Tla-o-qui-aht Traditional Research Council (TRC). We collaborated with the TFN administration and Ha'oom Fisheries Society in collecting data. In developing the results presented here, we synthesized information provided through the review of relevant documents (e.g., post-season reports, management protocols), 12 individual conversations with TFN resource managers, administrators, and Elders between August 2018 and November 2019, two TRC meetings in 2018 and 2019, co-development of written records of TFN cuwit (coho) management protocols with TFN's natural resources manager, and observation of five Salmon Roundtable ${ }^{2}$ meetings between November 2018 and February 2021. Most stories by elders were shared in a group during the TRC meetings. Individual conversations were held at the TFN offices, following introduction by a community liaison. Documents were acquired either through publically available records or were provided

\footnotetext{
${ }^{2}$ The WCVI Salmon Roundtables are bi-annual meetings between First Nations, commercial and recreational fishers, DFO, and other stakeholders to address salmon research, restoration, enhancement, and harvest planning efforts through co-management processes. Meetings are coordinated and moderated by West Coast Aquatic.
} 
directly by a TFN archivist, whose work was financially supported in part by this research. TFN leaders discussed and verified research findings with the authors. All research efforts were guided by a community liaison supported by the project who is listed as the fourth author on this paper.

\section{Positionality and Limitations}

The first and third authors are non-Indigenous researchers with white settler lived experience. The second author is Indigenous (Xwchíyò:m) and works with T'aaq-wiihak in negotiations and with Ha'oom in implementation. The fourth author is also Indigenous (Tla-o-qui-aht) and is a Tla-o-qui-aht Councillor, TFN Parks Project Coordinator, and plays a crucial role as a liaison and guide in this research. Other Tla-o-qui-aht collaborators have expressed support and approval of this paper and have for their own reasons chosen to not be listed as individual authors though we do work together to produce other allied research products of direct interest and value to TFN. We write with the intent to act as ethical allies to our Tla-o-qui-aht colleagues but not to speak for their experiences or interests. We extend gratitude for their leadership and guidance in this research.

When reviewing Nuu-chah-nulth values, sacred principles and relationships with salmon, we do not provide a complete summary or speak for Nuu-chah-nulth experience. As the first three authors are not Nuu-cha-nulth people, we cannot explain Nuu-chah-nulth worldviews or experience with complete accuracy, nor is it our rightful place to do so. Instead, we recommend the reader refer to work by Nuu-chah-nulth scholars (George, 2003; Atleo, 2004, 2011; Atleo C., 2008; Atleo M. R., 2008; Coté, 2019).

\section{RESULTS}

We separate our results into broad categories (worldview, management priorities, knowledge pluralism, and external relationships) to illuminate the key aspects of how knowledge is produced, valued, and deployed toward the management of cuwit and other salmon in TFN.

\section{Nuu-chah-nulth Relational Worldview and Traditional Practices}

TFN managers and Elders emphasized that all aspects of resource governance are informed by values grounded in the Nuu-chahnulth worldview and that decisions regarding the enhancement, restoration, and harvest of salmon populations are bound by these traditional values and principles. This includes ways of collecting, sharing, and using knowledge as well as processes of decision-making. Elders and managers stress that external partners learn about Tla-o-qui-aht values and worldview when engaging with Tla-o-qui-aht resource governance, especially in any attempts to connect western science and management with Tla-o-qui-aht practices. Here, we offer some broad descriptions of this worldview, focusing on what Tla-o-qui-aht Elders and fishery managers identified to be of key importance for
non-Nuu-chah-nulth practitioners to understand about salmon management in the Tla-o-qui-aht hahouthli.

The Nuu-chah-nulth worldview is grounded in the concepts of His-shuk-nish-t'sa-waalk, or "everything is one" and Iisaak, or "respect with caring" (Atleo, 2004, 2011). In this relational worldview, all components of the physical and spiritual worlds are understood as intimately connected; everything impacts everything else through close knit and sacred relationships (Atleo, 2004, 2011). Recognition, Respect, and Reciprocity are core principles in the Nuu-chah-nulth value system that honor and maintain these relationships (Atleo, 2011; TFN, 2020). Salmon, including cuwit (coho), hold a particular relational value within the Nuu-chah-nulth worldview. Traditional stories, for example, tell of the Salmon people as "blood relatives" and as sacred knowledge holders with whom the people hold an important reciprocal relationship: salmon offer themselves as food in exchange for the people's celebration by public ritual and for the care and guardianship of the rivers (Atleo, 2011). Following this tenet, much of Tla-o-qui-aht's management for salmon is focused on habitat restoration through traditional river guardianship to address the lasting detrimental impacts of forestry practices on freshwater habitat (DFO, 2002; TFN, 2020).

In addition to honoring valued relationships through respect and reciprocity in ceremony, habitat restoration, and harvest, Nuu-chah-nulth worldview guides traditional governance practices in political oversight of salmon management. For example, TFN's administrative natural resource management plans require approval of the Council of Hawit (hereditary chiefs). The Hawit review management plans to ensure that they follow His-shuk-nish-t'sa-waalk and Iisaak, uphold Tla-o-qui-aht's values, and honor traditional practices (TFN, 2020).

\section{Priorities: Enhancement, Restoration, Harvest}

Tla-o-qui-aht's protection of salmon is organized into three strategic programs: restoration of key habitat to improve salmon survivorship, enhancement of fish populations through Tlao-qui-aht owned hatcheries, and careful harvest management that upholds traditional practices and relationships without further threatening the fish stock. Restoration and enhancement programs support stock health and abundance, annual rates of return, and reproduction in salmon populations. Harvest programs address both home ${ }^{3}$ fisheries and commercial salmon fishing, though cuwit populations are currently too low to support commercial harvest within the hahouthli (TFN, 2020). Strategic programs are intended to "reinvigorate and maintain important relationships between cuwit and the Tla-o-qui-aht community," and support continued traditional practices in river guardianship, fish harvest, and ceremony (TFN, 2020). According to TFN resource managers and Elders, these strategies are maintained for multiple additional reasons including protecting culture, identity, and knowledge, honoring sacred relationships, abiding by Nuu-hah-nulth worldview, and enacting Tla-o-quiaht sovereignty in the hahouthli.

${ }^{3}$ TFN refers to FSC fisheries as "home" fisheries. 
Tla-o-qui-aht recognize that dwindling numbers of cuwit and other salmon threaten a food source and the sacred, reciprocal relationships between people, salmon, and rivers. All of TFN's cuwit management programs are designed to prioritize abundance and genetic diversity of coho. Only then does the maintenance of home fisheries follow, with commercial harvest as a long-term goal. This order of priorities was explained to us by a Tla-o-qui-aht fishery manager as: "putting the health and abundance of the fish first, so our relationship ... supports productive and healthy fish." River habitat restoration and enhancement of wild cuwit populations follows tenets of respect and care for the salmon. Harvest would enable salmon to perform their side of the relationship, but cannot be supported without proper respect, recognition and reciprocity through Tla-o-qui-aht guardianship. To prioritize harvest over restoration and enhancement would further harm cuwit populations. One Elder carefully differentiated this approach from sustainability frameworks in scientific fishery management: "We understand the concept of sustainability, but the way you [white people] use it frames the fish only in how they are useful to people. Sustainability sets our goals low rather than high enough to support both our needs and the fish's needs." In a Traditional Resource Council meeting, an Elder called this approach, "abundability." This order of priorities stands following the affirmation of TFN's commercial fishing rights. TFN intends to eventually hold full authority over a commercial cuwit fishery within the hahouthli, developed and managed through this philosophy, but does not plan to open a terminal commercial fishery in the hahouthli until cuwit populations have substantially increased (TFN, 2020).

\section{Knowledge Pluralism}

Although Nuu-chah-nulth worldview and traditional practices are central in Tla-o-qui-aht governance and management, scientific knowledge also plays an important role in informing decisions and monitoring management efforts. TFN works toward achieving management goals through application of the "best available knowledge" (TFN, 2020). TFN considers "best available knowledge" to include both Nuu-chah-nulth and scientific approaches to such tasks as stock assessments, river surveys, and monitoring environmental change. TFN's staff includes an Aboriginal Fishery Manager (AFM) and a Salmon Enhancement Manager (SEM), who are trained as traditional Guardians $^{4}$ and are well versed in scientific data collection and interpretation in the context of fisheries biology and management. Guardians hold important Indigenous knowledge of river systems and fish populations, abide by traditional practices of river stewardship according to Nuu-chah-nulth values, and guide traditional river walks to assess habitats, among other duties. They also coordinate their work with external collaborators, consulting with fishery biologists from

\footnotetext{
${ }^{4} \mathrm{TFN}$ Guardians represent the Nations' interests with regard to the hahouthli. In traditional Tla-o-qui-aht governance, individual keepers are trained from a young age as guardians and knowledge holders of specific systems (eg. river keepers or c'ac'ałuk). In the absence of active c'ac'ałuk, TFN Guardians currently fill those missing roles (A. Jackson, personal communication, February 11, 2021).
}

other management agencies such as Ha'oom and non-profits such as the Clayoquot Biosphere Trust. TFN Guardians oversee stock assessments, escapement surveys, and other scientific monitoring projects conducted by fishery biologists in their waters. They communicate with Tla-o-qui-aht fishers about the dates of salmon runs and the patterns of return to collect experiential knowledge of salmon populations in the rivers. Information from scientific surveys, river walks, and fisher consultation are utilized together in TFN's decision-making and development of restoration, enhancement, and harvest plans (TFN, 2020).

TFN's administration values this synthesis of traditional and scientific approaches to knowledge production for wellinformed management, particularly with regards to restoration and enhancement projects. Emerging scientific technology that may be useful for improving management strategies is considered positively, but carefully guided through Nuuchah-nulth worldview and TFN authority when applied with traditional knowledge practices to well-informed management plans. For example, the SEM and AFM expressed interest in the possibility of utilizing genomics to improve enhancement efforts. Important to this application, however, is that such tools are used concurrently to Tla-o-qui-aht knowledges and alongside traditional practices, and that their application is overseen by Tlao-qui-aht AFM, SEM and other relevant TFN staff or Guardian.

\section{External Governance Relationships}

Tla-o-qui-aht's pluralistic approach to knowledges is further evident in their external relationships. Clayoquot sound and coastal waters are shared with multiple stakeholders, including non-Indigenous commercial and recreational coho fishers. TFN currently does not have unilateral decision-making power in their watersheds. External collaborations with Ha'oom, T'aaq-wiihak, and local research and conservation groups are important in navigating this reality. The Hawit and elected Chief and Council appointed a Lead Negotiator to work with T'aaq-wiihak and Canada in reconciliation efforts. Ultimately, DFO oversees the conservation efforts regarding WCVI salmon, sets limits to total allowable catch across all harvest, and determines allocation of catch to recreational, commercial, and First Nations fisheries. In this context, it is advantageous to First Nations' to demonstrate their understanding of scientific reports and language while advocating for inclusion of their interests and knowledge in DFO management plans. When communicating with local DFO representatives during bi-annual Salmon Roundtables, for example, TFN's fishery managers use storytelling to convey Tla-o-qui-aht knowledge and advocate for Nuu-chah-nulth principles in addition to discussing scientific data sets presenting stock assessments, pathogen rates, and other statistics gathered and presented by DFO representatives through scientific methodologies. TFN considers such quantitative data alongside traditional knowledge when responding to DFO's draft regional management plans. Continuing research is contextualizing TFN's fishery management with external federal governance relationships and considering how the knowledge integration strategies employed by Ha'oom and DFO might compare to those used internally by TFN. 


\section{DISCUSSION}

Tla-o-qui-aht's management of rivers and salmon reflects a robust use of Indigenous and scientific ways of knowing, applied together to strategic management programs informed by an Indigenous worldview that honors relationships with salmon. IK and science are not treated as separate bodies of knowledge requiring translation of static pieces of information. Instead, they are actively co-constructed and mobilized together. Specific structures and individuals within TFN salmon governance and management facilitate this approach. TFN managers and Guardians-often the same person - play multiple roles, using different ways of knowing and communicating, enacting and guiding the ontological pluralities that shape TFN's river and fishery management practices. TFN's governance structures allow for the sharing of multiple knowledges in decisionmaking, guide traditional and scientific practice in cuwit management, and help to make the data or knowledge gathered legible to both traditional leaders and to external collaborators. Overall, TFN's cuwit management is grounded in Nuu-chah-nulth worldviews, protects Tla-o-qui-aht identity through maintenance of traditional practices, employs scientific methods, is guided by intergenerational knowledge, requires internal political approval, and is communicated strategically to navigate multiple and ontologically diverse internal and external governance relationships.

Our findings reinforce that productive, meaningful, and ethical use of Indigenous and scientific knowledges doesn't necessitate separation of and translation between knowledge bases and instead benefits from collaborative and pluralistic strategies. Whyte (2013) proposes a philosophical shift to conceptualizing Indigenous knowledges as collaborative practice and notes that many definitions of IK fit this framework which facilitates "cross-cultural and cross-situational collaboration among actors working for Indigenous and non-Indigenous institutions of environmental governance." Reid et al. (2020) point out that "it is the actions taken that matter most, rather that the words used to describe them" when considering pluralistic integration strategies through Indigenous frameworks like "Two-Eyed Seeing" or Etuaptmumk (Mi'kmaw). Epistemic plurality (Carter, 2017) is not the use of discrete pieces of information from multiple sources to understand a single reality, but rather the engagement with multiple perspectives, understandings, and ways of being to navigate shared and differentially experienced environmental realities which are highly context-specific. There is no singular "correct" approach to these strategies in praxis; Indigenous diversity and specificity must inform knowledge pluralism through particularities of local contexts (Howitt et al., 2009). Well-documented Indigenous frameworks include "Two Row Wampum" or Kaswentha (Haudenosaunee), "Double Canoe" or Waka-Taurua (Māori) and "Two Ways" or Ganma (Yolngu), all subject to contextual specificities (Bartlett et al., 2012; Muller, 2012; Maxwell et al., 2020; Reid et al., 2020). Along with these authors, we challenge dichotomous approaches to science and IK/TEK and instead point to Indigenous conceptualizations of collaborative, co-productive, multiplicative, or other congruent pluralistic strategies of knowledge production and application.

Indigenous leadership in facilitating the use of multiple knowledges within Indigenous territories is especially important. Indigenous leadership in knowledge integration supports Indigenous autonomy in environmental governance. This is important for improved local management outcomes and adaptive capacity in responding to environmental stressors such as climate change (Thompson et al., 2020; Whitney et al., 2020). Further, Indigenous leadership and self-determination are key to disrupting colonial legacies and harmful relationships of power (Reid et al., 2020). Resource governance implicates colonial pasts when western science takes precedence over or selectively uses IKs according to a western scientific management agenda and in the absence of Indigenous leadership (Muller et al., 2019). Rather than "integration" strategies that subsume Indigenous wisdoms into western paradigms, Indigenous leadership in strategies such as the above frameworks are necessary to "remedy...existing power relations, respect differences. and uphold, as opposed to diminish, their unique strengths"(Reid et al., 2020). Even the best intentioned knowledge integration efforts uphold colonial legacies and harmful power dynamics if directed within an Indigenous space by non-Indigenous peoples through hierarchical divisions of knowledges (Howitt et al., 2009; Coombes et al., 2014; Muller, 2014; Muller et al., 2019). In this case study, our collaborators emphasize that TFN leadership in research and management within the hahouthli supports TFN's agency and efforts toward self-determination. Throughout our research, our liaisons have guided us through traditional customs, deferral to TFN leadership in determining management objectives, and respectful consultation of Elders. They express that such engagement, following TFN's protocols of research permissions, better aligns the application of scientific methods and tools with First Nations' interests.

\section{CONCLUSION}

In this case study, Indigenous governance demonstrates effective pathways for applying science and Indigenous knowledges (IKs) to local salmon management efforts through pluralistic knowledge mobilization and ontological multiplicity. These pathways, coordinated and led by Indigenous peoples, reduce the frictions presented in dichotomous approaches to knowledge integration for locally scaled conservation and management efforts. The exact strategies identified in this study are contextually specific and not necessarily transferable to other Indigenous communities. However, the philosophical approach embedded in the practices where Indigenous and scientific knowledges are recognized as multiple concurrent ways of knowing and being is more broadly informative. This epistemic pluralism, through Indigenous leadership, enables Indigenous governance to direct knowledge production and application, disrupts colonial legacies, and resists scientific dominance in local practice without compromising accuracy of data or quality of management practices. We hope this illumination is helpful for researchers and managers seeking to concurrently apply 
Indigenous and scientific knowledges to fishery governance and management in a meaningful, ethically responsible, and effective manner. Ultimately, this shift in "integration" away from translation or assimilation and toward epistemic pluralism better supports Indigenous agency, empowers indigenous governance, and recognizes IKs as valid in efforts to improve efficacy and equity of fishery management.

\section{DATA AVAILABILITY STATEMENT}

The datasets presented in this article are not readily available. Most data used in this article are existing documents referenced within the text and were made available to the authors by Tla-oqui-aht First Nations, Ha'oom Fisheries, or West Coast Aquatic. Original data includes notes from conversations or observations of meetings and a few quotes from these data are included in the text. These notes are part of data under formal agreements made with research collaborators (Tla-o-qui-aht First Nations and Ha'oom Fisheries) wherein the authors would not distribute raw data without explicit permission by Tla-o-qui-aht First Nations. These agreements were made to ensure that Tla-o-qui-aht First Nations may retain ownership of Tla-o-qui-aht knowledge and the ability to determine how and when this knowledge is shared. These agreements were approved during ethics review by the Duke Campus IRB. Requests to access the datasets should be directed to JAB, julia.bingham@duke.edu.

\section{ETHICS STATEMENT}

The studies involving human participants were reviewed and approved by the Duke University Campus Institutional Review Board. The participants provided their written informed consent to participate in this study. Written informed consent was

\section{REFERENCES}

Agrawal, A. (1995). Dismantling the divide between indigenous and scientific knowledge. Dev. Change 26, 413-439. doi: 10.1111/j.1467-7660.1995.tb00560.x Atleo, C. (2008). From Indigenous Nationhood to Neoliberal Aboriginal Economic Development: Charting The Evolution of Indigenous-Settler Relations In Canada. Toronto, ON: Canadian Social Economic Hub.

Atleo, M. R. (2008). Watching to see until it becomes clear to you: metaphorical mapping - a method for emergence. Int. J. Qual. Stud. Educ. 21, 221-233. doi: 10.1080/09518390801998338

Atleo, R. E. (2004). Tsawalk: A Nuu-Chah-Nulth Worldview. Vancouver, BC: UBC Press.

Atleo, R. E. (2011). Principles of Tsawalk: An Indigenous Approach to Global Crisis. Vancouver, BC: UBC Press, doi: 10.5860/choice.50-0799

Ban, N., Wilson, E., and Neasloss, D. (2019). Strong historical and ongoing indigenous marine governance in the northeast pacific ocean: a case study of the kitasoo/xai'xais first nation. Ecol. Soc. 24:10. doi: 10.5751/ES-11091240410

Ban, N. C., Frid, A., Reid, M., Edgar, B., Shaw, D., and Siwallace, P. (2018). Incorporate indigenous perspectives for impactful research and effective management. Nat. Ecol. Evol. 2, 1680-1683. doi: 10.1038/s41559-018-0706-0

Bartlett, C., Marshall, M., and Marshall, A. (2012). Two-eyed seeing and other lessons learned within a co-learning journey of bringing together indigenous obtained from the individual(s) for the publication of any potentially identifiable images or data included in this article.

\section{AUTHOR CONTRIBUTIONS}

JAB, SM, GM, and TD designed the methodologies and developed the project with the permission and help of TFN collaborators. JAB and SM collected and analyzed the data. JAB led the writing of the manuscript. SM and GM provided substantial edits. SM and TD participated as experts in the elicitation process. All authors contributed critically to drafts and gave final approval for publication.

\section{FUNDING}

This research was carried out in conjunction with EPIC4 (Enhanced Production in Coho: Culture, Community, Catch), a project supported in part by Duke University, Vancouver Island University, the University of Victoria and the government of Canada through Genome Canada, Genome British Columbia, and Genome Quebec.

\section{ACKNOWLEDGMENTS}

We acknowledge the contribution of Terry Dorward, Saya Masso, Andrew Jackson, and others at Tla-o-qui-aht First Nations for their guidance in this research and in reviewing this text for accuracy. We extend gratitude to Tla-o-qui-aht First Nations, T'aaq-wiihak, and Ha'oom Fishing Society for their direction and support in this research. We acknowledge that several individuals beyond the listed authors have been instrumental in the writing of this article and are proponents of its publication, but have chosen for their own reasons to not be listed as individual authors.

and mainstream knowledges and ways of knowing. J. Environ. Stud. Sci. 2, 331-340. doi: 10.1007/s13412-012-0086-8

Berkes, F. (2009). Indigenous ways of knowing and the study of environmental change. J. R. Soc. New Zeal. 39, 151-156. doi: 10.1080/03014220909510568

Berkes, F. (2012). Sacred Ecology, Third Edn. New York, NY: Rutledge.

Bill C-68 (2019). An Act to Amend the Fisheries Act and Other Acts in consequence. SC 2019, c 14. Ottawa, ON: CanLII.

CanLII (2018). Ahousaht Indian Band and Nation v Canada (Attorney General). BCSC 633 2018. Ottawa, ON: CanLII.

Carter, J. A. (2017). "Epistemic pluralism, epistemic relativism and "hinge" epistemology," in Epistemic Pluralism. Series: Palgrave Innovations in Philosophy, eds A. Coliva and N. J. L. L. Pedersen (London: Palgrave), 229-252. . doi: 10.1007/978-3-319-65460-7_9

Coombes, B., Johnson, J. T., and Howitt, R. (2014). Indigenous geographies III: methodological innovation and the unsettling of participatory research. Prog. Hum. Geogr. 38, 845-854. doi: 10.1177/0309132513514723

Coté, C. (2019). hishuk'ish tsawalk-everything is one. Revitalizing placebased indigenous food systems through the enactment of food sovereignty. J. Agric. Food Syst. Community Dev. 9, 37-48. doi: 10.5304/jafscd.2019. 09A.003

Datta, R. (2015). A relational theoretical framework and meanings of land, nature, and sustainability for research with Indigenous communities. Local Environ. 20, 102-113. doi: 10.1080/13549839.2013.818957 
DFO (2002). West Coast Vancouver Island Coho. DFO Science Stock Status Report D6-06. Nanaimo, BC: Fisheries and Oceans Canada.

DFO (2019a). South Coast Salmon Bulletin \#13: 2019 Escapement Summary, All Salmon Species - Area 24: Clayoquot Sound. Nanaimo, BC: Fisheries and Oceans Canada.

DFO (2019b). South Coast Salmon Escapement Bulletin \#9: West Coast of Vancouver Island Stock Assessment for 15 November 2019 - All Salmon Species. Nanaimo, BC: Fisheries and Oceans Canada.

DFO (2020). South Coast Salmon Escapement Bulletin \#1: West Coast of Vancouver Island Stock Assessment for September 18, 2020 - All Salmon Species. Nanaimo, BC: Fisheries and Oceans Canada.

George, E. M. (2003). Living on the Edge: Nuu-Chah-Nulth History From an Ahousaht Chief's Perspective. Winlaw, BC: Sononis Press.

Howitt, R., Muller, S., and Suchet-Pearson, S. (2009). "Indigenous geographies," in International Encyclopedia of Human Geography, eds N. Thrift and R. Kitchin (Amsterdam: Elsevier), 358-364. doi: 10.1016/B978-008044910-4. 00705-7

Howitt, R., and Suchet-Pearson, S. (2003). "Ontological pluralism in contested cultural landscapes," in Handbook of Cultural Geography, eds K. Anderson, M. Domosh, S. Pile, and N. Thrift (Thousand Oaks, CA: SAGE Publications), 557-569. doi: 10.4135/9781848608252.n41

Howitt, R., and Suchet-Pearson, S. (2006). Rethinking the building blocks: ontological pluralism and the idea of "management." Geogr. Ann. Ser. B 88, 323-335. http://www.jstor.org/stable/3878377

Kimmerer, R. W. (2013a). Braiding Sweetgrass: Indigenous Wisdom, Scientific Knowledge and the Teachings of Plants. Minneapolis, MN: Milkweed Editions.

Kimmerer, R. W. (2013b). "The fortress, the river, and the garden: a new metaphor for cultivating mutualistic relationship between scientific and traditional ecological knowledge," in Contemporary Studies in Environmental and Indigenous Pedagogies: A Curricula of Stories and Place, eds A. Kulnieks, D. R. Longboat, and K. Young (Rotterdam: Sense Publishers), 49-76.

Kovach, M. (2010). Indigenous Methodologies: Characteristics, Conversations, and Contexts. London: University of Toronto Press.

Maxwell, K. H., Ratana, K., Davies, K. K., Taiapa, C., and Awatere, S. (2020). Navigating towards marine co-management with Indigenous communities onboard the Waka-Taurua. Mar. Policy 111:103722. doi: 10.1016/j.marpol.2019. 103722

Mistry, J., and Berardi, A. (2016). Bridging indigenous and scientific knowledge. Science 352, 1274-1275. doi: 10.1126/science.aaf1160

Mol, A. (1999). Ontological politics. a word and some questions. Sociol. Rev. 47, 74-89. doi: 10.1111/j.1467-954x.1999.tb03483.x

Muller, S. (2012). "Two ways': bringing indigenous and non-indigenous knowledges together," in Country, Native Title and Ecology, ed. J. K. Weir (Canberra, ACT: ANU E Press), 59-79.

Muller, S. (2014). Co-motion: making space to care for country. Geoforum 54, 132-141. doi: 10.1016/j.geoforum.2014.04.011

Muller, S., Hemming, S., and Rigney, D. (2019). Indigenous sovereignties: relational ontologies and environmental management. Geogr. Res. 57, 399-410. doi: 10. $1111 / 1745-5871.12362$

Price, M. H. H., English, K. K., Rosenberger, A. G., Macduffee, M., and Reynolds, J. D. (2017). Canada's wild salmon policy: an assessment of conservation progress in British Columbia. Can. J. Fish. Aquat. Sci. 74, 1507-1518. doi: 10.1139/cjfas-2017-0127

Reid, A. J., Eckert, L. E., Lane, J.-F., Young, N., Hinch, S. G., Darimont, C. T., et al. (2020). "Two-Eyed Seeing": an indigenous framework to transform fisheries research and management. Fish Fish. 22, 243-261. doi: 10.1111/faf.12516

Reid, B. (2020). Positionality and research: “Two-Eyed Seeing”. With a rural ktaqmkuk mi'kmaw community. Int. J. Qual. Methods 19, 1-12. doi: 10.1177/ 1609406920910841

Smith, L. T. (2012). Decolonizing Methodologies: Research and Indigenous Peoples, Second Edn. London: Zed Books.

TFN (2020). "Decision support tool for management of cuwit (coho salmon)," in Tla-o-qui-aht First Nations Lands and Resources, eds J. Bingham and S. Masso (Vancouver, BC: TFN).

Thompson, K. L., Lantz, T. C., and Ban, N. C. (2020). A review of indigenous knowledge and participation in environmental monitoring. Ecol. Soc. 25, 1-27. doi: 10.5751/ES-11503-250210

Thompson, K. L., Reece, N., Robinson, N., Fisher, H. J., Ban, N. C., and Picard, C. R. (2019). "We monitor by living here": community-driven actualization of a social-ecological monitoring program based in the knowledge of indigenous harvesters. Facets 4, 293-314. doi: 10.1139/facets-2019-0006

Truth and Reconciliation Commission (2015). Honouring the Truth, Reconciling for the Future: Summary of the Final Report of the Truth and Reconciliation Commission of Canada. Ottawa, ON: Truth and Reconciliation Commission.

Weiss, K., Hamann, M., and Marsh, H. (2013). Bridging knowledges: understanding and applying indigenous and western scientific knowledge for marine wildlife management. Soc. Nat. Resour. 26, 285-302. doi: 10.1080/08941920.2012.690065

Wheeler, H. C., and Root-Bernstein, M. (2020). Informing decision-making with Indigenous and local knowledge and science. J. Appl. Ecol. 57, 1634-1643. doi: 10.1111/1365-2664.13734

Whitney, C. K., Frid, A., Edgar, B. K., Walkus, J., Siwallace, P., Siwallace, I. L., et al. (2020). "Like the plains people losing the buffalo": perceptions of climate changimpacts, fisheries management, and adaptation actions by Indigenous peoples in coastal British Columbia, Canada. Ecol. Soc. 25, 1-17. doi: 10.5751/ ES-12027-250433

Whyte, K. (2013). On the role of traditional ecological knowledge as a collaborative concept: a philosophical study. Ecol. Process. 2:7. doi: 10.1186/2192-1709-2-7

Whyte, K. (2018). “What do indigenous knowledges do for indigenous peoples?," in Traditional Ecological Knowledge, eds M. K. Nelson and D. Shilling (Cambridge: Cambridge University Press), 57-82. doi: 10.1017/9781108552998.005

Conflict of Interest: The authors declare that the research was conducted in the absence of any commercial or financial relationships that could be construed as a potential conflict of interest.

Copyright (c) 2021 Bingham, Milne, Murray and Dorward. This is an open-access article distributed under the terms of the Creative Commons Attribution License (CC BY). The use, distribution or reproduction in other forums is permitted, provided the original author(s) and the copyright owner(s) are credited and that the original publication in this journal is cited, in accordance with accepted academic practice. No use, distribution or reproduction is permitted which does not comply with these terms. 